\title{
Lesions of Mature Barrel Field Cortex Interfere with Sensory Processing and Plasticity in Connected Areas of the Contralateral Hemisphere
}

\author{
V. Rema and Ford F. Ebner \\ Department of Psychology, Vanderbilt University, Nashville, Tennessee 37203
}

\begin{abstract}
Lesions of primary sensory cortex produce impairments in brain function as an outcome of the direct tissue damage. In addition, indirect lesion effects have been described that consist of functional deficits in areas sharing neural connections with the damaged area. The present study characterizes interhemispheric deficits produced as a result of unilateral lesions of the entire vibrissa representation of S-I barrel field cortex (BFC) in adult rats using single-neuron recording under urethane anesthesia. After unilateral lesions of adult BFC, responses of neurons in the contralateral homotopic BFC are severely depressed. Background (spontaneous) activity is reduced by $\sim 80 \%$, responses to test stimuli applied to the whiskers are reduced by $\sim 50 \%$, and onset of synaptic plasticity induced by trimming all but two whiskers ("whisker-pairing plasticity") is delayed over sevenfold compared with sham-lesion control animals. These deficits persist with only slight improvement for at least 4 months after lesion. Both fast-spiking and regular-spiking neuron responses are diminished contralateral to the lesion, as are cells above, below, and within the cortical barrels. Enriched environment experience increased the magnitude of responses and accelerated the rate of synaptic plasticity but did not restore response magnitude to control levels. Deficiencies in evoked responses and synaptic plasticity are primarily restricted to areas that share direct axonal connections with the lesioned cortex, because equivalently sized lesions of visual cortex produce minimal deficits in contralateral BFC function. These results indicate that interhemispheric deficits consist of remarkable and persistent decrements in sensory processing at the singleneuron level and support the idea that the deficits are somehow linked to the shared neural connections with the area of brain damage.
\end{abstract}

Key words: cortical lesions; stroke; brain injury; diaschisis; synaptic plasticity; enriched environment

\section{Introduction}

Lesions of the cerebral cortex produce many complex responses to brain injury. Well documented hypoexcitability effects resulting from cortical lesions include extensive hypometabolism (Feeney and Baron, 1986; Andrews, 1991; Dietrich, 1998; Witte, 1998; Nudo, 1999), reductions in blood flow (Lagreze et al., 1987; Dobkin et al., 1989; Baron, 1991; Infeld et al., 1995), decreases in glucose metabolism (Cappa et al., 1997), and low amplitude of EEG activity (Juhasz et al., 1997) in the contralateral as well as ipsilateral cortex after brain trauma. Stroke patients are known to have seizures (Kotila and Waltimo, 1992; So et al., 1996), and one suggested mechanism is that a focal stimulation can initiate seizure discharge against a background of reduced activity (Prince et al., 1997; Witte, 1998). Some of the general metabolic effects are found over widespread areas, whereas other deficits appear to be restricted to areas in the brain linked by their neural connections to the area of damage. The term "diaschisis" was introduced by von Monakow (1914) to designate the restricted distant effects he deduced from neurological examination of stroke patients. The

\footnotetext{
Received March 14, 2003; revised Sept. 15, 2003; accepted Sept. 15, 2003.

This work was supported by National Institutes of Health Grant NS-13031. We thank Anita Sankaran for expert assistance with the histology.

Correspondence should be addressed to Dr. V. Rema, Scientist V, National Brain Research Center, Nainwal Mode, Manesar, Haryana-122 050, India. E-mail: rema@nbrc.ac.in.

Copyright $\odot 2003$ Society for Neuroscience $\quad 0270-6474 / 03 / 2310378-10 \$ 15.00 / 0$
}

fundamental etiology of distant deficits remains unclear. Many studies have identified features of brain function and behavior that are impaired for periods of time after cortical lesions and then recover. The present study was designed to measure the effect of lesions in the barrel field cortex (BFC) on single neurons in the homotopic, axonally connected region of the contralateral hemisphere.

Whiskers on the rat's face transduce sensory stimuli and activate cells in the somatosensory cortical region known as whisker barrel field cortex through well described sensory pathways. It is important to note that the BFC is an area with interhemispheric connections that are assumed to provide at least part of the conduit for signaling the presence of a lesion. Connectional studies by Korelek et al. (1988) showed a complicated pattern of commissural projections between the left and right BFC that are assumed to support the bilateral-evoked responses that are produced in response to whisker stimulation (Pidoux and Verley, 1979; Shuler et al., 2001). Thalamic fibers from the ventral posterior nucleus terminate densely in the layer IV barrel centers, whereas commissural fibers (Olavarria et al., 1984) and the thalamic inputs from the medial division of the posterior nucleus terminate predominantly in the septal zones around, above, and below the cortical barrels ( $\mathrm{Lu}$ and Lin, 1992). In contrast to layer $\mathrm{IV}$, the commissural projections that terminate in the layers above the barrels are more widely distributed, such that supra- 
granular layer cells and many apical dendrites of layer $\mathrm{V}$ barrel column neurons would be expected to receive synapses from commissural fibers.

For the experiments described here, unilateral lesions were made in the BFC. The analysis involved recording from single cortical neurons, under urethane anesthesia, in vivo at various times after the lesion was made to measure changes in cortical neuron spontaneous activity, their response to sensory stimulation, or their ability to produce activity-dependent plasticity.

\section{Materials and Methods}

Animals. For this study, 39 adult male Long Evans rats (250-350 gm) were used. All procedures were approved by the Vanderbilt Animal Care and Use Committee and were in compliance with National Institutes of Health guidelines.

Procedure for producing cortical lesions. Cortical lesions were produced by ablation or by applying $150 \mathrm{~mm}$ NMDA (Huang et al., 1998) to the surface of the exposed dura with the goal of removing only the superficial layers of the cortical representation of the mystacial vibrissae (whiskers) in SI cortex (i.e., the BFC). Using aseptic techniques under Nembutal anesthesia $(50 \mathrm{mg} / \mathrm{kg})$, adult [postnatal day (P) 60] rats were placed in a stereotaxic head-holder. The soft tissues were retracted from over the calvarium on the right side. A bone opening slightly larger than the BFC was made with a dental burr from 3.5 to $7 \mathrm{~mm}$ lateral to the midline and from 1 to $4 \mathrm{~mm}$ posterior to bregma keeping the dura intact. The head was rotated so that the medial and lateral edges of the bone opening were horizontal to create a well for the NMDA application. For the ablation lesion, an area 4 to $6.5 \mathrm{~mm}$ lateral to the midline and 1.5 to $3.5 \mathrm{~mm}$ posterior to bregma was removed by subpial aspiration using a finecaliber sterile Pasteur pipette attached to a low-vacuum pump. Special care was taken to ensure that the tissue removed did not extend to the white matter at the time of surgery. For visual cortex lesions, the opening was $6-9 \mathrm{~mm}$ posterior to bregma and $1.5-4.5 \mathrm{~mm}$ lateral to midline. Any bleeding was controlled by applying small pieces of gelfoam. After each surgical manipulation, the area was carefully cleaned with sterile sponges, the bone flap was replaced with dental cement, the soft tissues were sutured, and topical antibiotic ointment (Neoporacin) was applied. Sham-operated rats had the bone flap removed over the BFC and the surface of dura washed with saline before the bone flap was replaced and the soft tissue and skin were sutured. Systemic antibiotics were administered routinely (oxytetracycline, $100 \mathrm{mg} / \mathrm{kg}$, i.m.). At the time of surgery, fluids were given to control dehydration. On recovery, the animals behaved normally to observation (i.e., they moved their whiskers synchronously, and they ate and drank and interacted with their cage mates similar to preoperative behavior). At various postoperative survival times, the responses of the neurons in the D2 whisker barrel-column from layers I to V in the hemisphere opposite the lesion were tested (Fig. 1). Sham-operated and normal rats with and without whisker pairing (WP) were used as controls. Because the neuronal responses from sham-operated rats were indistinguishable from neuronal responses from normal unoperated rats, the data from the sham-operated and normal rats were pooled.

Surgery and anesthesia for electrophysiology. Electrophysiological responses of cortical neurons were recorded under urethane anesthesia. Rats were injected intraperitoneally with urethane anesthesia (30\% aqueous solution; $1.5 \mathrm{gm} / \mathrm{kg}$ ). Rectal temperature was maintained near $36^{\circ} \mathrm{C}$ with an electronically controlled heating pad. The head was placed in a stereotaxic apparatus, and an opening was made in the skull to expose the $\mathrm{BFC}$ of the left (unlesioned) hemisphere. Small openings were made in the dura to introduce a carbon fiber electrode into cortex. Neurons were sampled in radial penetrations within the D2 whisker barrel column. During the recording session, the depth of anesthesia was maintained at a constant level by monitoring the burst rate of cortical neurons at 2-4 $\mathrm{Hz}$ (Armstrong-James and Fox, 1987). Burst-pause activity occurs in layer $\mathrm{V}$ neurons and is propagated to the other cortical layers, where it can be detected at the recording site via the recording electrode by listening to the audiomonitor, and can be correlated with neurological signs of anesthetic depth. In addition to the usual signs of surgical level anesthesia such as the absence of a corneal reflex, little or no response to pressure
A

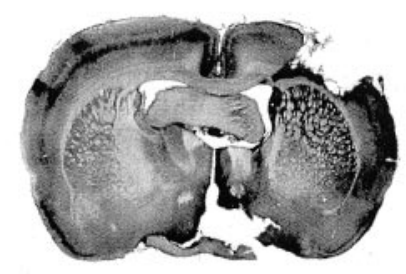

B

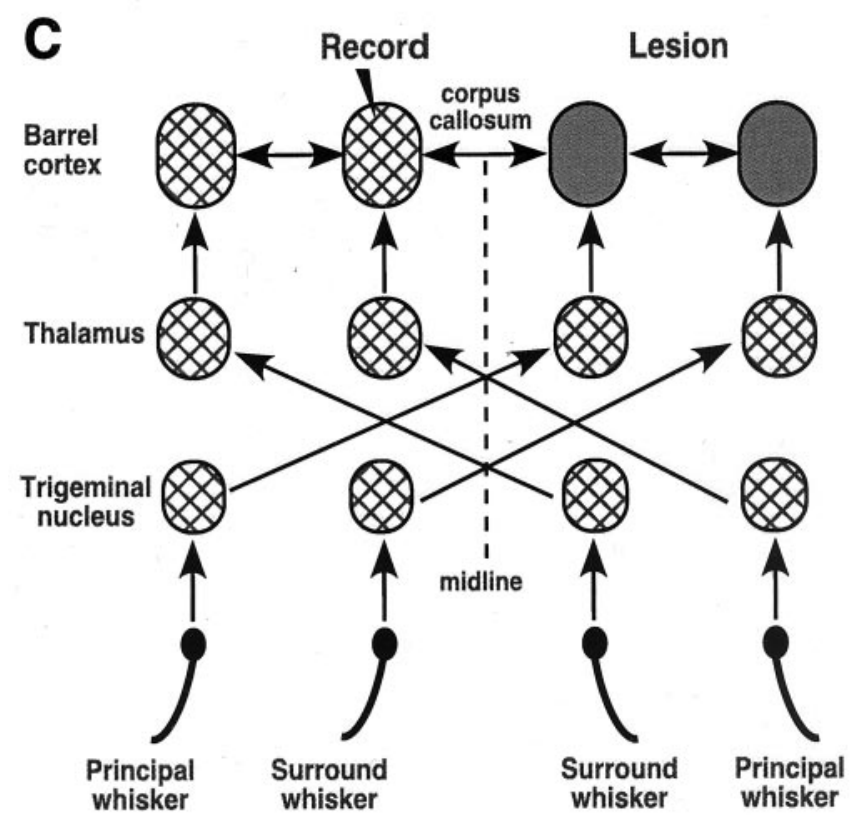

Figure 1. A, Photomicrograph of rat brain coronal section stained for NMDARI subunit showing the extent of a typical ablation lesion of the BFC. $B$, Schematic diagram of the rat brain showing the location of the BFC lesion, the control lesion in visual cortex (VC), and the recording site in the D2 barrel column of the contralateral hemisphere. C, Schematic diagram showing the pathways from the principal whisker (D2) to its barrel column in the contralateral cortex. Surround whiskers project to their own barrels and activate cells in the D2 barrel column through intracortical pathways.

applied to a limb, and no spontaneous whisker movements, the depth of anesthesia was monitored and corrected either by injecting supplementary urethane ( $10 \%$ of the original dose) when the burst rate exceeded 4 $\mathrm{Hz}$ or allowing the anesthesia to wear off if the burst rate was $<2 \mathrm{~Hz}$.

Whisker stimulation. Individual whiskers on the right side of the face were stimulated by positioning a thin wooden rod glued to one end of a piezoelectric "bimorph" ceramic wafer just below the whisker, $4-5 \mathrm{~mm}$ from the skin. The wafer was deflected by a computer-gated current producing a $300 \mu \mathrm{m}$ trapezoidal up-down movement of the free end with rise and fall times of $0.5 \mathrm{msec}$ and a total stimulus duration of 3 msec. Fifty stimuli delivered at one per second were used for each block of trials. One block of stimulus trials was presented to whisker D2 and then to each of its immediate neighbors (D1 and D3) for each cell recorded.

Electrophysiological recording and data analysis. Carbon fiber microelectrodes (Armstrong-James and Millar, 1979) were used to record action potentials. Movement of the black electrode tip through the pia could be monitored under surgical microscope and was aided by an audiomonitor to detect the onset of neuronal noise. Cell isolation was achieved by a time-amplitude window discriminator (BAK Electronics, Germantown, MD). Accepted action potential waveforms were monitored on a digital storage oscilloscope (Nicolet Instrument Technologies, Madison, WI) during recording to ensure continued proper isolation of single neurons and to measure spike duration. Neurons were isolated from layers I, II/III, IV, and V. 
Peristimulus time histograms (PSTHs), raster plots, and latency histograms at $1 \mathrm{msec}$ resolution were generated on-line using a Cambridge Electronics Design processor (model 1401 plus; Cambridge Electronics Design, Cambridge, UK) and personal computer (Dell Computer Company, Round Rock, TX). All raw data on timing of action potentials were stored for additional off-line analysis. For all forms of PSTH analysis, spike counts in each bin were adjusted for spontaneous activity by subtracting the mean bin count for activity generated $100 \mathrm{msec}$ before the stimulus averaged over 50 trials. For analyzing statistical significance, nonparametric tests were used, either Mann-Whitney $U$ test (MWU) or Wilcoxon rank sum test (Wilcoxon).

Recording-modified responses to sensory stimuli. Whisker pairing was used to induce synaptic modifications in cortical neurons. WP was performed by trimming all but two whiskers on one side of the face. For the present study, all of the whiskers except D2 and D1 on the right side were cut close to the skin daily for $7 \mathrm{~d}$ before physiological analysis. The experimental animals were usually housed in standard plastic rat cages with at least one normal cage mate during the intervals between the initial whisker clipping and the start of the recording session. Whisker-trimmed animals appeared from observation to use the intact paired whiskers to palpate, explore, and "whisk" in a normal manner. At the start of the recording session, the intact D1 and D2 whiskers were trimmed so that all of the whiskers were the same length $(3-5 \mathrm{~mm})$. Rats with all whiskers intact (nonwhisker-paired animals) were used as controls for whiskerpaired animals. These were housed with one other rat before investigation similar to the experimental rats.

Identification of recording sites. At the end of electrophysiological recording, cortical penetrations were relocated and marked by passing a DC of $2 \mu \mathrm{A}$ for $5-10 \mathrm{sec}$ (electrode tip positive). The current produced a spheroidal lesion $\sim 50 \mu \mathrm{m}$ in diameter that was easily seen in cytochrome oxidase-stained histological sections. When electrode penetrations were $100 \mu \mathrm{m}$ apart, alternate penetrations were marked with a lesion, and this enabled locations of unmarked penetrations to be determined by interpolation. When the penetrations are $>200 \mu \mathrm{m}$ apart, each penetration was marked. After the lesions were placed, the rats were given a lethal dose of Nembutal and perfused with $0.1 \mathrm{~m}$ PBS followed by $4 \%$ buffered paraformaldehyde. The brains were removed and postfixed overnight in paraformaldehyde followed by cryoprotection in 10,20, and 30\% sucrose in $0.1 \mathrm{M}$ PBS. The neocortex was separated from underlying structures and flattened between glass slides. Tangential sections were cut at $60 \mu \mathrm{m}$ and processed for cytochrome oxidase activity to localize the recording sites (Wong-Riley and Welt, 1980). A neuron was considered to be within the $\mathrm{D} 2$ barrel column if the recording site was localized within the vertical and horizontal bounds of the cytochrome oxidase-stained D2 barrel. Only cells located histologically within, above, or below the D2 barrel are included in these studies.

Environmental enrichment. Lesioned and sham-operated rats were first allowed to recover from the surgery for $1 \mathrm{~d}$ and then placed in a complex environment for $12 \mathrm{hr}$ each day during the dark period of the $12 \mathrm{hr}$ light/dark cycle for either 7 or $34 \mathrm{~d}$. The complex environment was a large $1 \mathrm{~m}^{3}$ cage filled with novel stimuli (plastic objects or toys) that were changed each day, ramps to reach platforms containing food pellets, and five cage mates (Rema and Ebner, 1999).

\section{Results}

Spontaneous activity and response to sensory stimulation

Eight days after an ablation lesion of BFC (BFC ablation), the average background or spontaneous activity of neurons from layers $\mathrm{I}-\mathrm{V}$ in the homotopic contralateral BFC was reduced by $80 \%$ compared with controls under our recording conditions ( $p=0.0001$; MWU). Likewise, the responses of the barrel column neurons from layers I-V to test stimuli applied to the principal whisker D2 summed with the two row surround whiskers D1 and D3 (summed response magnitude of the three whiskers D1, D2, and D3 for block of 50 stimuli applied to each whisker) were reduced by $47 \%$ below control values ( $p=0.0001$; MWU) (Fig. 2). The reduction in response to stimulation of each whisker is shown in Figure 2. The data from 77 neurons from 4 cases of BFC ablation was compared with the data obtained

\section{A Spontaneous Activity}
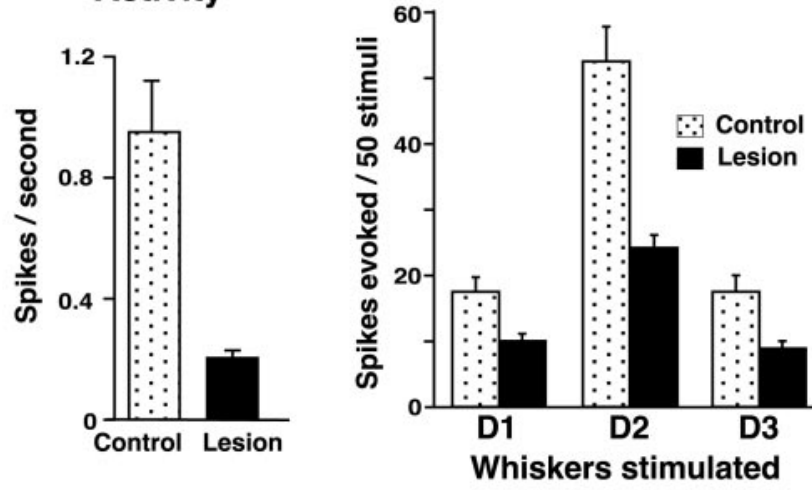

C Single Cell Evoked Response

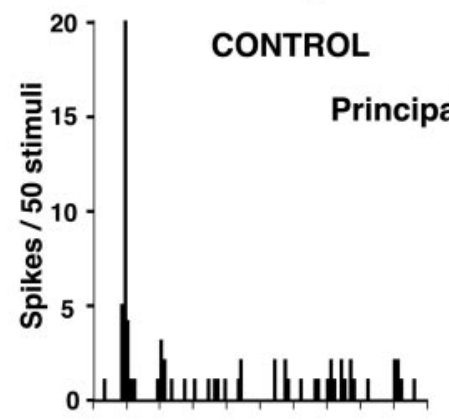

LESION

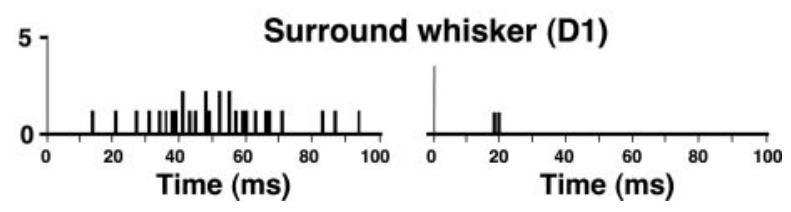

Figure 2. Spontaneous and evoked responses of neurons in the D2 barrel column. A, Bar graph showing the level of spontaneous discharges in D2 barrel column neurons in contralateral hemisphere of BFC ablation-lesioned animals and in control animals. The average background activity of neurons from all layers of cortex show an $\sim 80 \%$ decrease in lesioned animals compared with controls. $B$, Histograms representing mean response magnitudes for 51 neurons from three control animals and 77 neurons from four BFC ablation-lesioned animals. For each neuron, 50 stimuli were applied to each of the three D-row whiskers. Error bars represent SEM. Lesions produced $\sim 47 \%$ reduction in the evoked dischages in the contralateral hemisphere compared with controls. C, Poststimulus time histograms of single-cell responses to principal D2 and surround D1 whisker stimulation contralateral to control and lesion hemispheres (stimulus onset is at 0 msec time point). Note the nearly complete absence of longer-latency spikes as well as the reduction in the short-latency component after a lesion in the contralateral cortex in these single-cell responses.

from 51 neurons from 3 control cases ( 2 sham-operated, 1 unoperated normal).

\section{Whisker-pairing plasticity}

Previous studies have shown that whisker-pairing plasticity (WPP) is significant in the superficial layers within $24 \mathrm{hr}$ in normal adult rat cortex under standard cage conditions (Diamond et al., 1994) and even in layer IV barrels after $15 \mathrm{hr}$ if the animals are placed in an enriched environment (Rema et al., 1998b). After a cortical ablation lesion, WPP did not occur in cortex contralateral to a lesion, although whiskers were paired for $7 \mathrm{~d}$. Surprisingly, WP exacerbated the already suppressed response. Specifically, the BFC ablation animals without WP experience showed a $47 \%$ decrease to whisker stimuli, whereas after $7 \mathrm{~d}$ of WP (86 


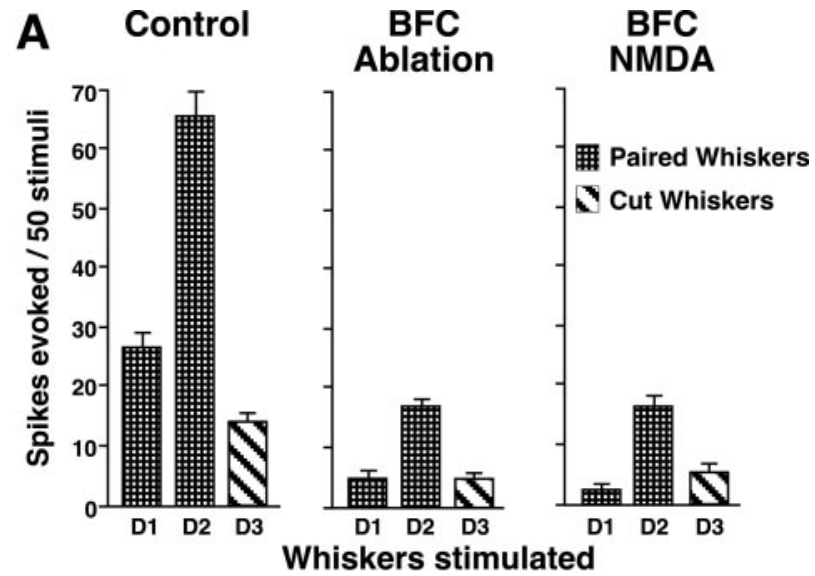

B Principal whisker D2

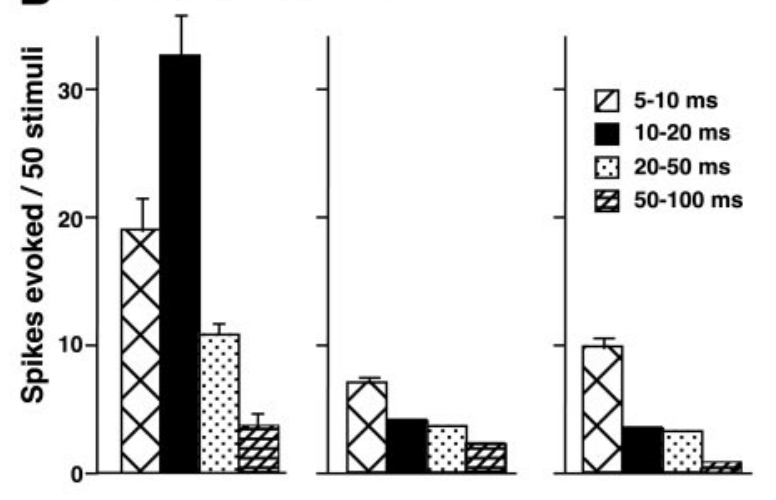

Paired Whisker D1
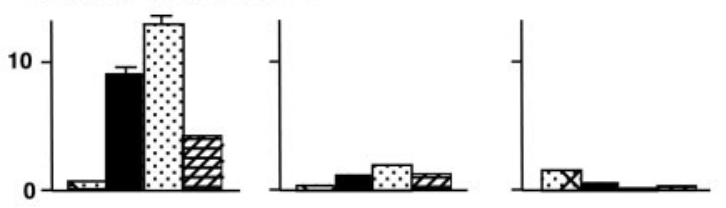

Cut Whisker D3

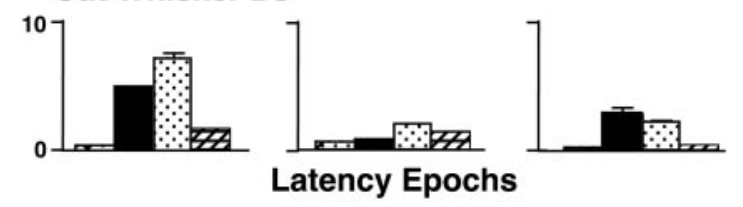

Figure 3. Cortical neuron responses to whisker stimulation in controls and in both ablation and excitotoxic NMDA-lesioned animals $8 \mathrm{~d}$ after lesion with $7 \mathrm{~d}$ of whisker pairing (2-8d after lesion). $A$, Histograms showing evoked responses to stimulation of whiskers D1, D2, and D3 in controls and lesioned animals. D2 barrel column neurons in control animals (72 neurons from 3 animals) show a significant increase in response to the principal D2 whisker and a shift in response magnitude from D1:D3 ratio of 1 to being significantly biased toward the active, intact, surround D1 whisker (compare with no whisker-pairing levels in Fig. 2). Both principal and surround whisker responses are reduced after ablation (86 cells, 4 animals) and NMDA lesions (25 neurons, 3 animals). After contralateral barrel field lesions, there is no increase in the principal whisker responses and no shift toward the active surround whisker after $7 \mathrm{~d}$ of whisker pairing. $B$, Segregation of response magnitude into responses in different latency epochs within 3-100 msec after whisker stimulation. Lesions in the opposite hemisphere reduce responses at all latencies, with a particularly marked effect on the short-latency (5-10 and 10-20 msec after stimulus) responses produced by the principal (D2) whisker. (SE on the bars without markers is too small to be seen at this scale.)

neurons from 4 animals), the responses were further reduced to a $75 \%$ decrease as compared with whisker-paired controls ( 72 neurons from 3 animals). Thus, instead of the normal increase in response to the active intact whiskers (WPP), there was an addi-
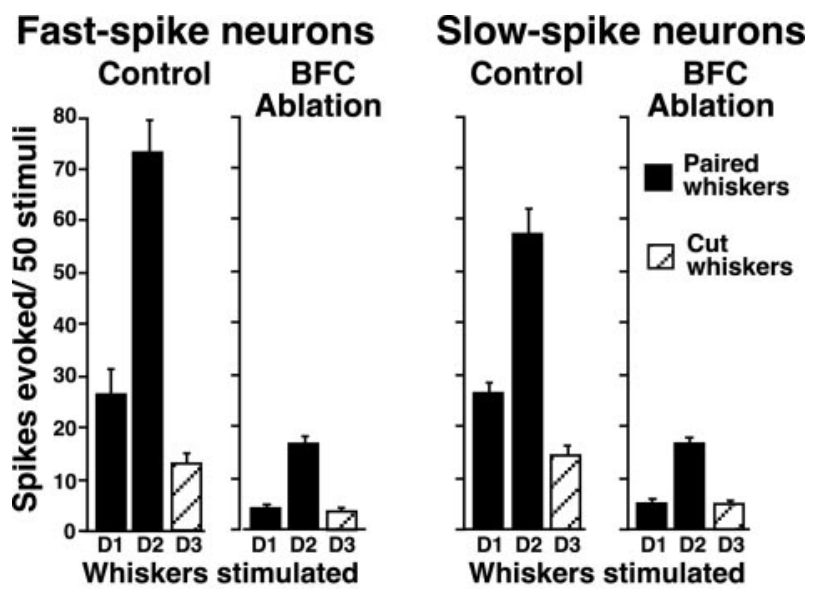

Figure 4. Effect of BFC ablation lesion on fast-spiking and slow-spiking neurons. Separation of barrel column neurons by their spike duration of $<0.75 \mathrm{msec}$ (fast-spiking neurons) and $\leq 0.75 \mathrm{msec}$ (slow-spiking neurons) shows that both neuronal classes are affected by the contralateral BFC lesion. Fast-spiking neurons typically show a higher spontaneous discharge and greater response to whisker stimulation, but both fast- and regular-spiking neurons have reduced responses and fail to show a shift toward the intact surround whisker after $7 \mathrm{~d}$ of whisker pairing. Mean response magnitudes of 31 fast-spiking neurons and 55 slow-spiking neurons from lesioned animals were compared with 38 fast-spiking neurons and 34 slowspiking neurons from control animals (see Fig. 3 from which these data were reclassified).

tional reduction in response magnitudes in whisker-paired, ablation-lesioned rats (Fig. 3).

To determine whether this effect was specific to the type of lesion, WPP was tested in rats with excitotoxic NMDA lesions. The NMDA lesions were limited only to the whisker barrel cortex (BFC NMDA). With 15 min of exposure to $150 \mathrm{~mm}$ NMDA, the lesion extended down to layer IV of the cortex as shown previously (Huang et al., 1998). This type of lesion is different from ablation lesions because there are no broken blood vessels or transected fibers of passage but only neuronal cell death. As done for the BFC ablation, the NMDA-lesioned rats were whiskerpaired (D1 and D2 whiskers intact) after a $24 \mathrm{hr}$ recovery period from surgery. After $7 \mathrm{~d}$ of WP, spontaneous activity and evoked activity were recorded from BFC NMDA animals (25 neurons from 3 animals) and were compared with the responses of BFC ablation animals and control animals. Both types of lesions led to a similar detrimental effect on spontaneous activity level (BFC NMDA, $0.29 \pm 0.05 / \mathrm{sec}$; BFC ablation, $0.24 \pm 0.03 / \mathrm{sec}$, compared with $1.1 \pm 0.08 / \mathrm{sec}$ for controls; $p=0.0001$; MWU for both BFC ablation and BFC NMDA compared with controls) (see Fig. 8). Evoked responses were also reduced after both BFC ablation (BFC ablation vs control; $p=0.0001$; MWU) and BFC NMDA lesions (BFC NMDA vs control; $p=0.0001$; MWU). When cortical cell responses are segregated into latency epochs, both the short latency 5-10 msec (presumed thalamocortical AMPA receptor-dependent component) and the longer latency 10-100 msec [presumed corticocortical NMDA receptor (NMDAR)-dependent components] (Armstrong-James et al., 1993; Rema et al. 1998a) were depressed after whisker pairing (Fig. 3). Because ablation lesions and excitotoxic lesions had similar effects on the neuronal responses, we used only one type of lesion, ablation lesions, for all other experiments presented in this study.

We were interested in determining whether both excitatory and inhibitory neurons were affected by the lesion; thus, the sample was separated by spike duration to provide an initial insight into this question. In the rat barrel cortex, the fast-spiking neurons (those with action potentials $<0.75 \mathrm{msec}$ in duration) make 
Control

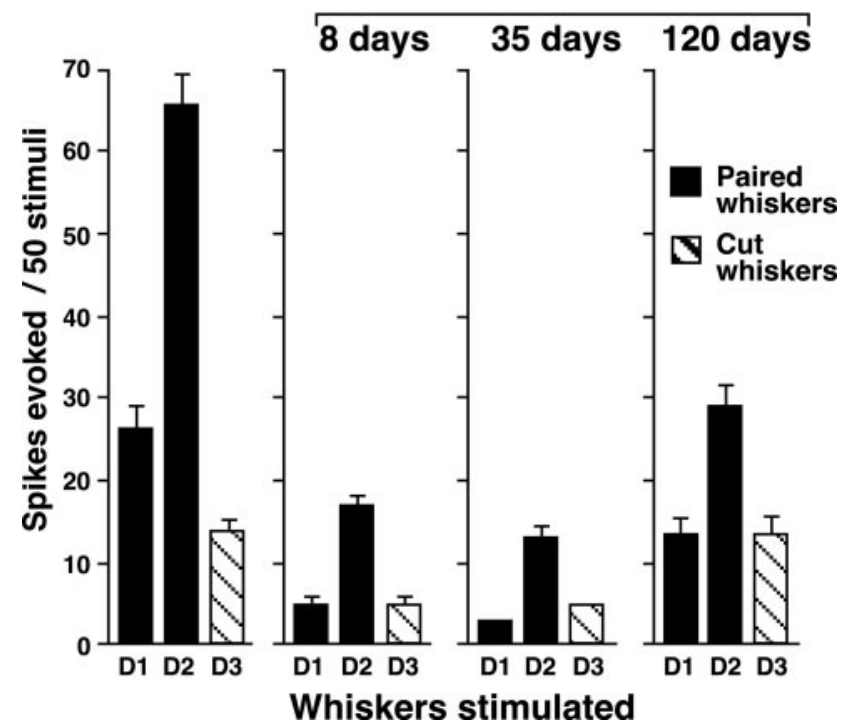

Figure 5. Effect of the length of recovery period after BFC ablation lesion on neuronal responses and plasticity in the contralateral barrel cortex. Longer survival times show that, after unilateral BFC lesions, neuronal responses in the contralateral hemisphere do not recover quickly. At each survival time, whisker trimming was done during the $7 \mathrm{~d}$ before the end of the 8,35 , or $120 \mathrm{~d}$ postlesion period. The animals were kept under standard cage conditions ( 2 per plastic cage) during the postlesion survival period. Response magnitudes for 86 neurons from 4 rats $8 \mathrm{~d}$ after lesion, 30 neurons from 3 rats $35 \mathrm{~d}$ after lesion, and 58 neurons from 3 rats $120 \mathrm{~d}$ after lesion was compared with the responses from 72 neurons from 3 control animals. There is a clear trend toward higher responses after 4 months, but plasticity fails to return compared with controls. (SE on the bars without markers is too small to be seen at this scale.)

up a different morphological and functional group from the regular-spiking or slow-spiking neurons (action potentials $>0.75$ msec in duration). There is strong evidence that nearly all fastspiking neurons are inhibitory neurons and the regular-spiking neurons are predominantly excitatory (McCormick et al., 1985; Keller and White, 1987; Connors and Gutnik, 1990; Agmon and Connors, 1992). Figure 4 shows histograms of mean response magnitudes comparing 31 fast-spiking and 55 slow-spiking neurons from four BFC ablation animals and 38 fast-spiking and 34 slowspiking neurons from control animals. Both classes of neurons are equally affected by the lesion and showed diminished response to sensory stimuli (BFC ablation vs control; $p=0.0001$; MWU, for both fast- and slow-spiking neurons). Neither set of neurons showed any increase in response magnitude or shift in bias toward the intact whisker after $7 \mathrm{~d}$ of whisker trimming (Fig. 4).

The earliest moment that activity is depressed has not been defined. However, by $8 \mathrm{~d}$ after lesion, contralateral activity is unquestionably reduced. The timing of the earliest significant deficits in different layers is the subject of ongoing studies. The impairment persists for as long as 4 months. The decrement of responsiveness in the homotopic, contralateral BFC cortex occurs, despite the fact that the sensory pathway used to test the unlesioned barrel cortex is not directly damaged by the lesion in any known way. The deficits seen at $8 \mathrm{~d}$ after lesion show no sign of improvement (recovery) at $35 \mathrm{~d}$ after lesion (control vs BFC ablation lesion; $p=0.0001$; MWU for both 8 and $35 \mathrm{~d}$ after lesion). Response magnitudes were recorded from 72 neurons in 3 control animals, 86 neurons in 4 BFC ablation-lesioned animals after $8 \mathrm{~d}$ of survival, and from 30 neurons in 3 BFC ablationlesioned animals after $35 \mathrm{~d}$ of survival. By 4 months after the lesion, D2 barrel column neurons (58 neurons in 3 animals)

\section{A Control}
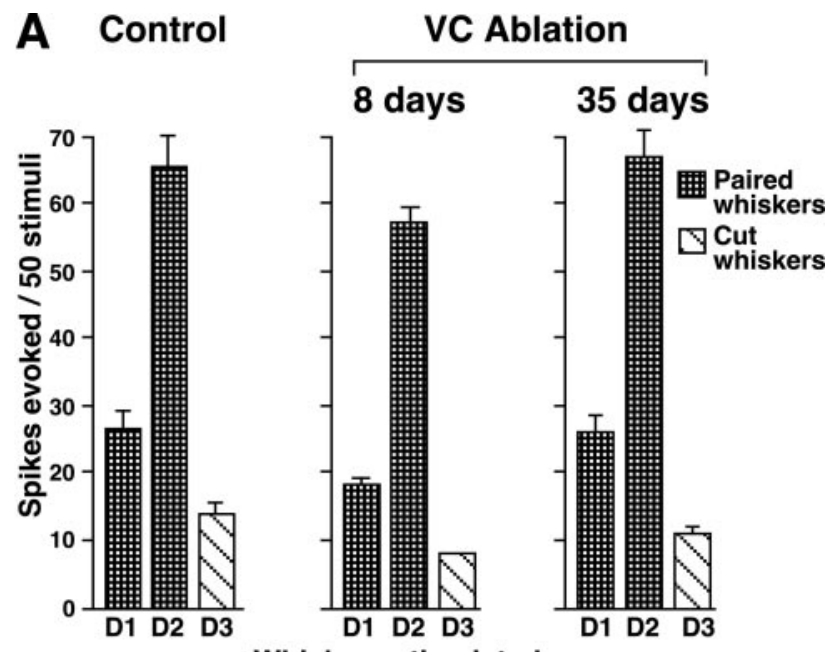

B Principal whisker D2

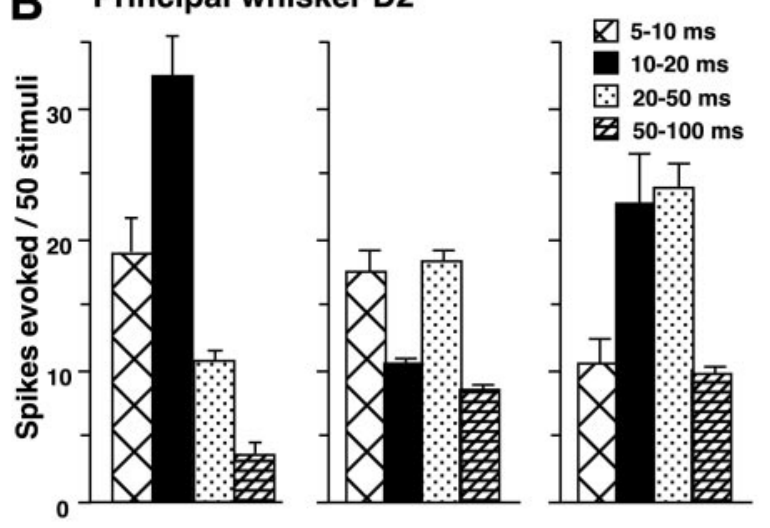

Paired Whisker D1

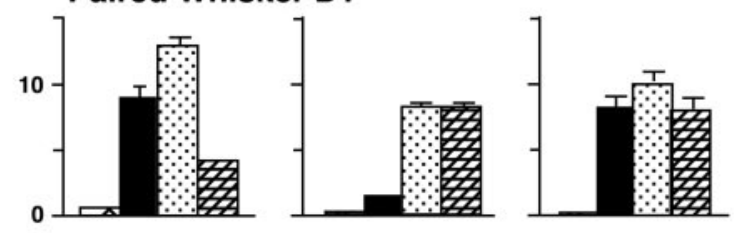

Cut Whisker D3

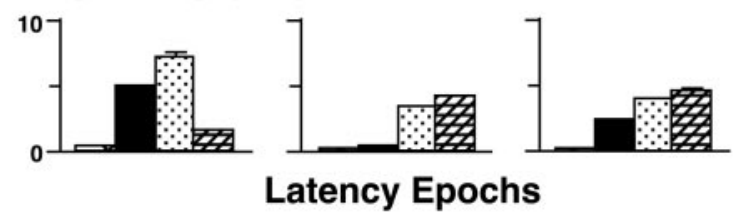

Figure 6. Effects of lesions in visual cortex on responses in the contralateral BFC. Responses and plasticity in the contralateral $\mathrm{BFC}$ are much less affected by visual cortex lesions, with a transient nonsignificant decrease in response magnitude $8 \mathrm{~d}$ after lesion (54 neurons from 4 animals), which appear to recover after 35 postlesion days (26 neurons from 2 animals) compared with controls. See Results for additional details.

showed improvement in their response magnitudes to stimulation of the D2, D1, and D3 whiskers. The mean recovery was 53\% of the response levels (summed response magnitudes for 3 whiskers per 50 stimuli after $7 \mathrm{~d}$ WP) of control animals (72 neurons in 3 animals) and $212 \%$ recovery compared with $8 \mathrm{~d}$ after lesion responsiveness. However, compared with controls, the responses were still significantly lower for D1 and D2 (control vs BFC ablation lesion; $p=0.0001$; MWU for both D1 and D2) 
but were not significantly different for D3 ( $p=0.96$; MWU). Although there is an increase in response magnitudes after 4 months of recovery, there was no WPP under standard cage conditions (Fig. 5).

\section{Effect of visual cortex lesions}

Lesions of equivalent size, but located posterior to the BFC (visual areas I and II), were made to test whether the lesion effect is specific to the homotopic contralateral cortex or a quite general response to damage to any portion of contralateral cortex (Fig. 6). Lesions in visual areas may have had negative effects on parts of the brain that we did not assay. However, in the contralateral BFC at $8 \mathrm{~d}$ after lesion (54 neurons in 4 animals), there is slight but nonsignificant reduction in both spontaneous activity (control vs visual cortex lesion, $p>0.1$; MWU) and sensory driven responses (control vs visual cortex lesion; $p>0.2$; MWU). In contrast, at $35 \mathrm{~d}$ after visual cortex lesions (26 neurons in 2 animals), the spontaneous activity was significantly depressed (control vs visual cortex lesion; $p=0.002$; MWU) (see Fig. 8) without a significant reduction in evoked activity compared with controls (control vs visual cortex lesion; $p>0.3$; MWU). The transient decreases appeared to be greatest in evoked responses at intermediate latencies of 10-20 msec after stimulus. Visual cortex lesions did not produce a negative effect on the rate of WPP in the contralateral barrel cortex (Fig. 6).

\section{Effect of enriched environment}

Placing animals in a stimulating, social, large, three-dimensional environment had a significant positive effect on cortical function in only $8 \mathrm{~d}$ after a cortical lesion (Fig. 7). After 1 week in an enriched environment, summed response magnitudes of neurons ( 51 neurons from 3 animals) in the D2 barrel-column to the inputs of the principal and two surround whiskers (summed response of D1, D2, and D3 whiskers per 50 stimuli, sequentially) were elevated from $27 \%$ in the standard cages to $83 \%$ of controls in the enriched environment. Nonetheless, the principal whisker D2 response remains particularly depressed ( $p<0.0012$; MWU), whereas the surround whisker responses, although reduced, are not significantly different from controls ( $p>0.1$ for D1 and D3; $p>0.1$; MWU). The poststimulus latency domain in which the response remained most depressed is from 10-20 msec after stimulus. Despite the elevated responses, the bias toward greater activity generated by the active surround whisker (paired whisker) compared with the cut surround whisker (WPP) is not present at $8 \mathrm{~d}$ after lesion, even after the enriched environment experience (D1 vs D3; $p>0.3$; Wilcoxon). After $35 \mathrm{~d}$ in the enriched environment, the response

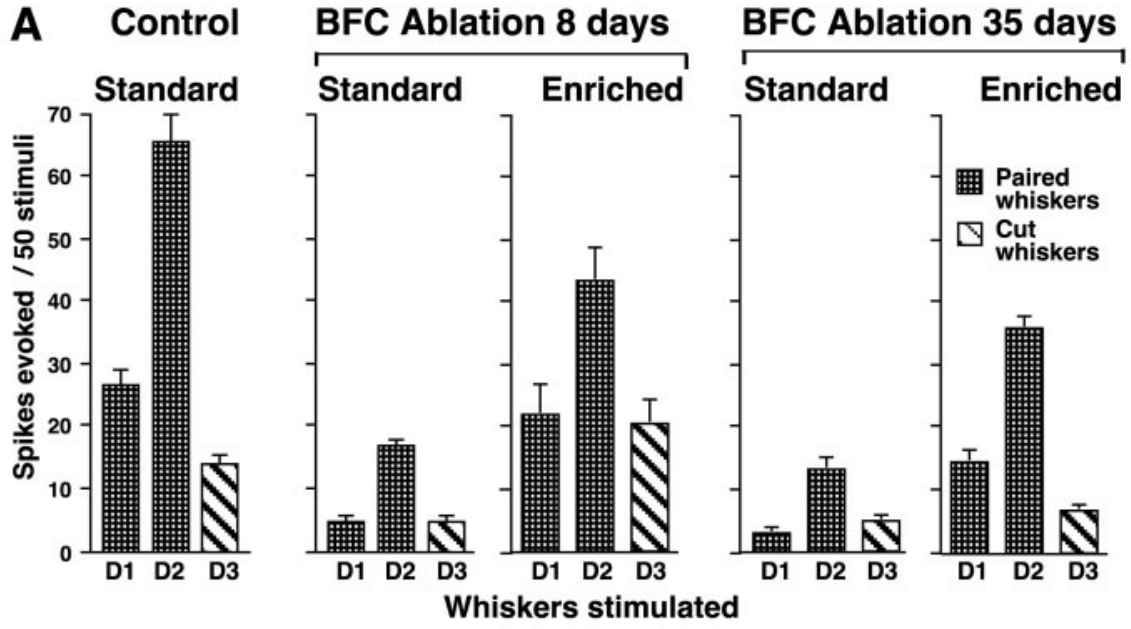

\section{B Principal Whisker D2}
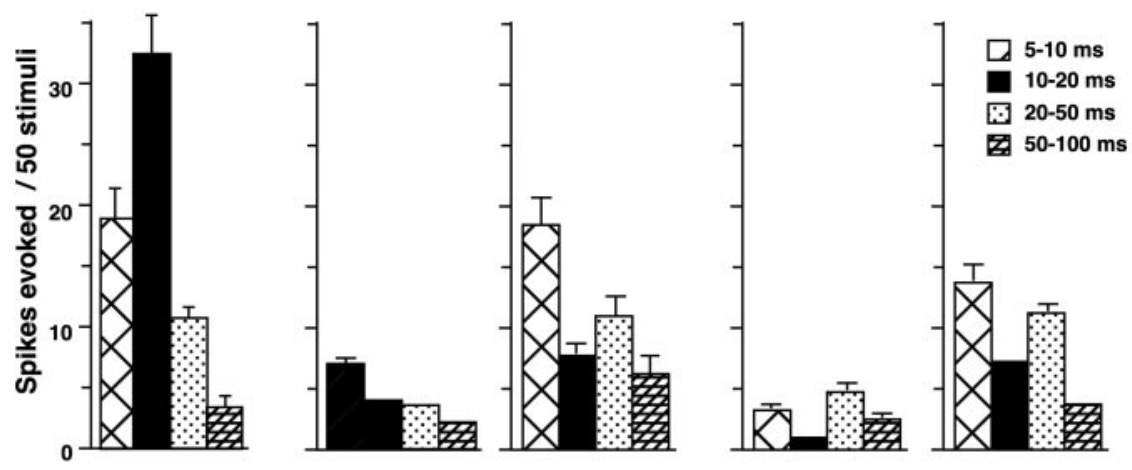

\section{Paired Whisker D1}
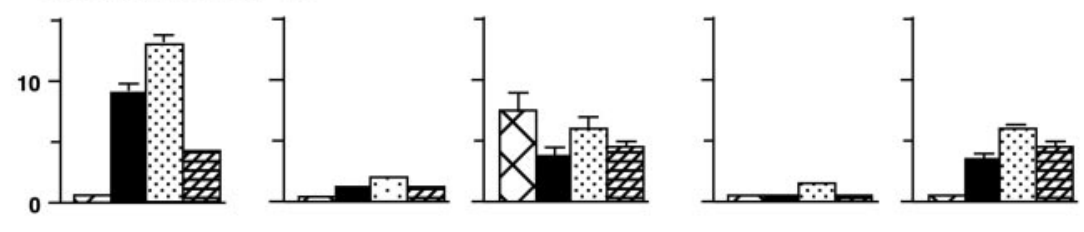

Cut Whisker D3
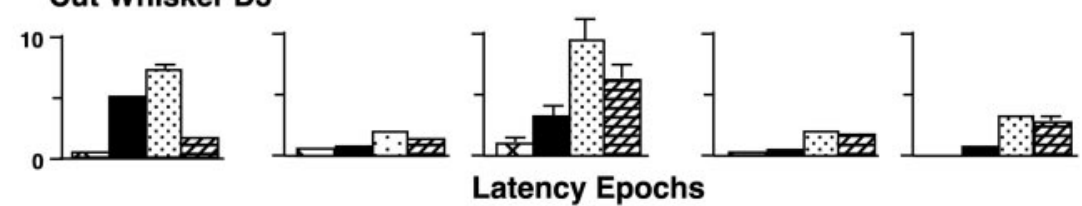

Figure 7. Effect of enriched environment experience on the return of function contralateral to BFC lesions in adult rats. The enriched experience was assayed at two postlesion times, $8 \mathrm{~d}$ ( 51 neurons from 3 animals) and $35 \mathrm{~d}$ ( 71 neurons from 3 animals) with the last 7 postlesion days being whisker-paired. After $8 \mathrm{~d}$ of enriched experience, the neurons show better responses than after $120 \mathrm{~d}$ of regular experience but share the absence of shift toward the intact surround whisker. After $35 \mathrm{~d}$, cortical cell responses are still depressed but are responsive to the whisker-trimming challenge by showing a significant shift (see Results) toward the intact surround whisker.

magnitudes of D2 barrel column neurons (71 neurons in 3 animals) do not remain elevated at the levels seen after $8 \mathrm{~d}$ of enriched environment exposure. However, the modifications necessary to produce WPP do return, and a significant shift in response to the intact paired whiskers occurred (D1 vs D3; $p<$ 0.001; Wilcoxon). The net effect of longer enrichment was to reinstate synaptic modification, despite subnormal response levels. Latency analysis shows that responses at all latencies are affected by the ablation lesion in both standard as well as enriched environment (Fig. 8). 


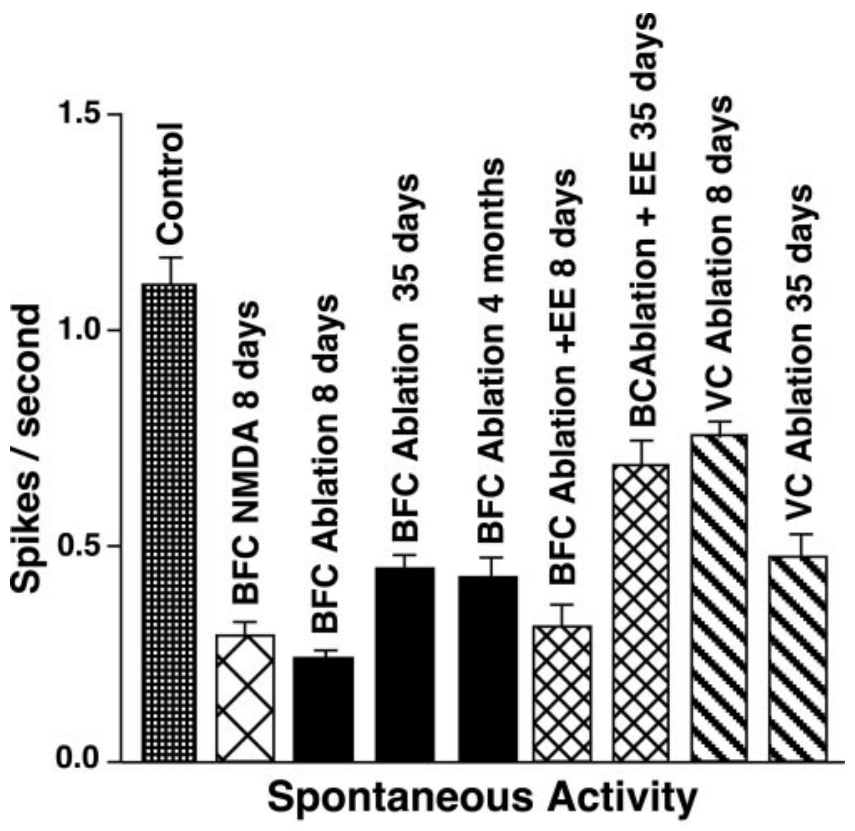

Figure 8. Spontaneous activity levels (spikes per second) of neurons under the nine conditions described in Results. Conditions are identified above each bar. Cortical lesions have a long-lasting negative effect on spontaneous discharges of the neurons in the contralateral hemisphere. EE, Enriched environment; $V C$, visual cortex; $A B L$, ablation lesion; days, total survival period with whisker-pairing experience taking place during the last $7 \mathrm{~d}$. Note that only EE for $35 \mathrm{~d}$ and nonhomotopic $\mathrm{VC}$ lesions produce spontaneous activity in the cortex that is at least within $50 \%$ of controls.

\section{Lesion effects on cells in different layers}

Neurons in supragranular (layer III), granular (layer IV barrels and septa), and infragranular (layer V) layers could be separated on the basis of their depth from the cortical surface and position relative to fiduciary lesions and analyzed as separate groups to identify layer-specific effects. The data from this analysis for each condition are shown in Table 1. Three important findings emerge from this analysis. First, the response of cells in all layers to whisker stimulation are depressed by a lesion in the contralateral hemisphere. Both principal and surround whisker responses are affected, with the greatest decrement in response to principal whisker stimulation (II/III, 50\%; IV, 56\%; V, 66\% reduction). At $8 \mathrm{~d}$ after an ablation lesion, cells show an average $40 \%$ decrease in response in layers II/III, a 48\% decrease in layer IV, and a $64 \%$ decrease in layer $\mathrm{V}$ compared with control values.

Second, in every layer, $7 \mathrm{~d}$ of whisker pairing abnormally depresses the response to test stimuli even further when applied to the intact whiskers. The percentage reduction of the average response of the two active whiskers D1 plus D2 is equal to $72 \%$ in II/III, $76 \%$ in IV, and $83 \%$ in V, whereas that to the cut whisker was also substantial (D3: 67\% in II/III, 58\% in IV, and 74\% in V). Third, the depressed responses in different cortical layers do not recover over time with standard cage experience but do show improvement in response levels and even a restoration of whisker-pairing plasticity after $35 \mathrm{~d}$ of exposure to an enriched environment. The greatest shift toward higher responses to the intact surround whisker was observed in layer IV.

\section{Discussion}

The present results document a significant physiological response deficit after a cortical lesion that occurs in the region of the contralateral sensory cortex, which shares interconnections with the damaged cortex. The results confirm the phenomenon of interhemispheric diaschisis in sensory cortex at the singleneuron level using natural sensory stimuli. The deficits are manifest as decrements in neuronal excitability, impairment in responsiveness to sensory inputs, and delays in the rate of synaptic modification in cortical synapses. After a cortical lesion, the responses of neurons in all layers of the contralateral cortex are severely depressed for an extended period of time. The suppression of spontaneous activity as well as stimulus-driven activity suggests that some of the mechanisms controlling overall cortical excitability as well as the ability of cortical neurons to respond to sensory stimuli are affected by the lesion (Fig. 8). Current ideas about factors affecting these features of cortical function suggest that the lesion has a negative impact on several mechanisms, some topographically localized and others global and widespread in their effects. The total cascade of events in the pathogenesis of this interhemispheric effect and how they change over the remaining lifetime of the animal is still sketchy. However, the fact that the deficits occur in areas linked by neural connections to the damaged area suggests that the total loss of activity arising from the lesioned area could be an important factor, in addition to the inevitable response that occurs as a result of the lesion-induced neuronal anterograde and retrograde degeneration.

\section{Impact of cortical lesions on neuronal anatomy}

In the lesioned hemisphere, the commissurally projecting cells and their axons are destroyed and, at the same time, reciprocal commissural projections could initiate anterograde and retrograde reactions. As seen in the thalamus (Ross and Ebner, 1990; Al-Abdulla and Martin, 2002), retrograde degeneration of neurons after cortical damage is likely to occur in areas with axonal connections to the lesioned site. There is clear evidence from studies of the brainstem that when the axons of lower motor neurons are damaged, the synapses are "stripped" or removed from their dendrites by a type of microglial cell, and the facial nucleus neurons remain synaptically disconnected until the axons regenerate back to the denervated muscle (Blinzinger and Kreutzberg, 1968). Synaptic reorganization of this type has not been demonstrated in the cerebral cortex, where long-axon regeneration does not occur. Available evidence suggests that the cortex shows a very different anatomical response to injury of the contralateral cortex. One anatomical change after cortical lesions is that the cells in layer $\mathrm{V}$ of the homotopic contralateral cortex show a lengthening of their basal dendrites with an increase in dendritic branching and synapses per unit length of dendrite. These changes peak at $18 \mathrm{~d}$ after a cortical lesion and return to prelesion values by 3 months after the lesion (Jones et al., 1996). Similar dendritic responses have been reported in response to growth factor levels applied to cortical slice cultures, such as brain-derived neurotrophic factor (McAllister et al., 1995), suggesting that alterations in growth factor function and dendritic morphology could affect the structure and function of contralateral cortex after cortical lesions.

\section{Impact of lesions on cortical excitability}

The localization of the sensory deficits to the homotopic contralateral cortex suggests that some part of the reaction is related to the direct connections between the hemispheres. Even when exposure to an enriched environment increased spontaneous activity levels, the background excitability remained below control values (Fig. 4). Thalamocortical activity could regulate cortical excitability and influence the rate and amount of recovery of function. Inputs arising from the nonspecific (intralaminar) thalamocortical projection systems have been shown to provide a 
Table 1. Average responses (mean \pm SEM) of neurons in different layers of barrel cortex

\begin{tabular}{|c|c|c|c|c|c|c|c|c|c|}
\hline \multirow[b]{2}{*}{ Conditions } & \multicolumn{3}{|c|}{ Layer II/III } & \multicolumn{3}{|c|}{ Layer IV } & \multicolumn{3}{|l|}{ Layer V } \\
\hline & D1 & $\mathrm{D} 2$ & D3 & D1 & D2 & D3 & D1 & $\mathrm{D} 2$ & D3 \\
\hline Control, no WP & $15(2)$ & $45(7)$ & $15(4)$ & $14(2)$ & $57(4)$ & $13(1)$ & $22(9)$ & $65(14)$ & $17(6)$ \\
\hline BFC ablation, 8 d survival, no WP & $12(3)$ & $24(4)$ & $9(1)$ & $10(1)$ & $25(2)$ & $9(1)$ & $7(1)$ & $22(3)$ & $8(2)$ \\
\hline Control $7 \mathrm{~d}$ WP & $23(4)$ & $57(6)$ & $12(3)$ & $23(3)$ & $81(6)$ & $12(2)$ & $35(7)$ & $53(7)$ & $19(3)$ \\
\hline BFC ablation, $8 \mathrm{~d}$ survival, $7 \mathrm{~d}$ WP & $5(1)$ & $17(2)$ & $4(1)$ & $6(1)$ & $19(2)$ & $5(1)$ & $3(1)$ & $12(1)$ & $5(2)$ \\
\hline NMDA lesion, $8 \mathrm{~d}$ survival, $7 \mathrm{~d}$ WP & $1(3)$ & $16(5)$ & $7(4)$ & $3(1)$ & $17(1)$ & $5(2)$ & $2(1)$ & $15(4)$ & $5(3)$ \\
\hline BFC ablation, $35 \mathrm{~d}$ survival, $7 \mathrm{~d}$ WP & $5(2)$ & $18(5)$ & $7(2)$ & $2(1)$ & $9(1)$ & $3(1)$ & $0(1)$ & $7(3)$ & $2(2)$ \\
\hline BFC ablation, $120 \mathrm{~d}$ survival, $7 \mathrm{~d}$ WP & $10(2)$ & $22(2)$ & $15(3)$ & $16(3)$ & $38(5)$ & $12(4)$ & $15(4)$ & $25(4)$ & $13(3)$ \\
\hline BFC ablation, $8 \mathrm{~d}$ survival plus EE plus $7 \mathrm{~d}$ WP & $12(3)$ & $22(3)$ & $18(5)$ & $21(3)$ & $38(4)$ & $17(2)$ & $11(3)$ & $31(3)$ & $10(2)$ \\
\hline BFC ablation, 35 d survival plus EE plus $7 \mathrm{~d}$ WP & $15(3)$ & $32(4)$ & $11(2)$ & $12(2)$ & $37(3)$ & $2(1)$ & $16(5)$ & $24(4)$ & $10(3)$ \\
\hline
\end{tabular}

robust, bilateral, synchronizing influence on the patterned spontaneous activity seen in the BFC during slow-wave sleep and under anesthesia (Fox and Armstrong-James, 1986). Thalamocortical projection systems have been suggested as a likely candidate to support the recovery of function after unilateral or even large bilateral cortical lesions that involve both SI and SII cortices (Pazos et al., 1995). A missing link still exists between a lesion in one hemisphere and the mechanisms affected that would need to be conceptually located primarily in the contralateral thalamus. This is a potentially important dimension of interhemispheric communication that warrants additional study.

Another candidate mechanism capable of downregulating cortical excitability would be changes in the modulatory inputs to cortex that use acetylcholine or monoamines as neurotransmitters. A directly relevant example of this effect is seen in the markedly reduced percentage of cortical cells, from 69 to $22 \%$, that shows increased discharge to iontophoretically applied acetylcholine at 3-4 d after lesions in the contralateral SI cortex (Zarei et al., 2001). When the responses to acetylcholine return at 20-21 $\mathrm{d}$, they are predominantly opposite in sign (i.e., inhibitory rather than excitatory), which would tend to prolong a state of low excitability. The same study showed that noradrenergic effects also reverse, with $\sim 50 \%$ of cortical neurons shifting from a prelesion decrease in response after release of norepinephrine ("inhibition") to the majority of cells showing an increased response to release at $21 \mathrm{~d}$ after lesion. These results are consistent with the observation that catecholamine agonist drugs, combined with physical activity and training, can enhance long-term recovery of function after cortical lesions (Hurwitz et al., 1991; Feeney, 1997).

The decrease in cortical excitability reported here could be the result of a decrease in levels of spontaneous and driven excitatory neurotransmission or an increase in inhibition in the contralateral cortex. Previous reports of changes in evoked potentials or EEG contralateral to cortical lesions have provided evidence for no change or a decrease in amplitude of evoked potentials in the first $24 \mathrm{hr}$ after lesions (for review, see Andrews, 1991). Our results showing a depression of responses were nonetheless unexpected in light of several reports of a general disinhibition effect after photothrombotic lesions or middle cerebral artery occlusion of the posterior parietal area in rat cortex. Inhibition in brain slices is diminished in both the ipsilateral and large extents of the contralateral hemisphere (Buchkremer-Ratzmann et al., 1996; Buchkremer-Ratzmann and Witte, 1997), and this result is correlated with a bilateral increase in the size of hindlimb receptive fields in SI cortex after lesions posterior to the SI cortex (Reinecke et al., 2003). Several differences in design make these results difficult to directly compare with our results, such as their lesions being located posterior to SI between somatic sensory and pri- mary visual cortex, and in the in vitro slice studies having the modulatory inputs to cortex disconnected. However, as discussed below, excitability changes can be direct or indirect and are expected to change as a function of time after the lesion occurs. Thus, more detailed studies are necessary.

It is possible that there are generalized effects on cortical excitability that extend over most of the contralateral hemisphere at certain times after a cortical lesion. There was a trend toward longer-term diminished spontaneous activity that did not appear at earlier times in our visual cortex lesion cases. The observations of Clarey et al. (1996) seem relevant to such time-dependent changes. When they cooled one hemisphere for a short time, they found disinhibition of responses contralaterally, but prolonged cooling reversed the trend and introduced a suppression of responses to somatosensory stimulation. The temperatures recorded indicated that this suppression was not likely to be simply attributable to cooling the entire brain.

Another change produced by lesions in sensory areas that has received little attention is that the ongoing neural activity associated with neural information processing comes abruptly to an end in the lesioned area. The neurons in the opposite hemisphere that are connected to the lesion would detect the lesion as a sudden reduction to near zero of input activity arising from commissural inputs. Additional studies are needed to clarify the role of activity in producing interhemispheric effects after cortical lesions.

\section{Impact of cortical lesions on cortical plasticity}

In normal and sham-operated animals, whisker pairing produces highly reproducible and significant increases in neuronal response to stimulation of the two intact whiskers within $1 \mathrm{~d}$. These increases in response magnitude constitute a sensitive index of activity-dependent response modification called whisker-pairing plasticity (Diamond et al., 1993; Armstrong-James et al., 1994), in which increased response and decreased response are produced in the absence of any CNS lesion. Cortical lesions have a negative impact on whisker-pairing plasticity, in that the reduced responses to whisker stimulation after cortical lesions are also diminished by the high-activity bias generated by the two intact whiskers. The abnormal suppression of active whisker responses after $7 \mathrm{~d}$ of whisker pairing is not unprecedented, because it has been reported after prenatal alcohol exposure (Rema and Ebner, 1999) and after depletion of acetylcholine from the SI cortex (Sachdev et al., 1998). Theory predicts that to produce this activity-based response depression, the mechanisms supporting the threshold for synaptic strengthening must set the threshold at an unobtainable high level. If this occurred in the areas connected to the lesion, then the theory by Bienenstock et al. (1982) predicts that the high-input activity would then become effective in producing continual long-term depression but not long-term potentiation, 
and the response levels that depend on those synapses would be driven down but not eliminated (Benuskova et al., 2001).

NMDA receptor-dependent mechanisms are also adversely affected by cortical lesions. WPP depends on functional NMDAtype glutamate receptors during the period between whisker trimming and brain analysis (Rema et al., 1998a). Long latency responses to whisker stimulation depend heavily on NMDAR activation (Armstrong-James et al., 1994), and these responses were especially depressed in the present experiments. Considerable evidence suggests that NMDAR blockade immediately after a cortical lesion may be neuro-protective against the glutamate released by dying cells (Belayev et al., 1995). WPP can also be blocked by the depletion of acetylcholine from SI cortex (Sachdev et al., 1998), which would reduce calcium entry through NMDA receptors via muscarinic cholinergic receptor actions (Segal and Auerbach, 1997). Synaptic plasticity can be partially restored by training the animals on a whisker-dependent, gap-crossing task (Sachdev et al., 2000). Such recovery of function is remarkably similar to the $80 \%$ recovery of function on the same task after photothrombotic lesions of the barrel cortex (Hurwitz et al., 1990). The present results also show significant acceleration of plasticity by enriched environment experience. Of course, the cortical response to injury is very complex, and all NMDA-based changes need not be direct. For example, cortical lesions have been shown to downregulate $\mathrm{GABA}_{\mathrm{A}}$ receptor subunit expression, and this effect is blocked by $(+)-5$-methyl-10,11-dihydro$5 \mathrm{H}$-dibenzo [a,d] cyclohepten-5,10-imine maleate, an NMDA receptor antagonist (Redecker et al., 2002). The details of the cellular mechanisms underlying recovery of function in each paradigm remain to be worked out. However, a number of lines of evidence suggest that behavioral challenges that produce significant increases in sensory activity, in combination with drugs linked to accelerated learning (Boyeson and Feeney, 1990; Hurwitz et al., 1991; Witte and Stoll, 1997; Witte, 1998), may have potential for restoring sensory cortex function after cerebral vascular accidents.

\section{References}

Agmon A, Connors BW (1992) Correlation between intrinsic firing patterns and thalamocortical synaptic responses of neurons in mouse barrel cortex. J Neurosci 12 1:319-329.

Al-Abdulla NA, Martin LJ (2002) Projection neurons and interneurons in the lateral geniculate nucleus undergo distinct forms of degeneration ranging from retrograde and transsynaptic apoptosis to transient atrophy after cortical ablation in rat. Neuroscience 115:7-14.

Andrews RJ (1991) Transhemispheric diaschisis. Stroke 22:943-949.

Armstrong-James M, Fox K (1987) Spatiotemporal convergence and divergence in the rat SI "barrel" cortex. J Comp Neurol 263:265-281.

Armstrong-James M, Millar JM (1979) Carbon fibre microelectrodes. J Neurosci Methods 1:279-287.

Armstrong-James M, Welker E, Callahan CA (1993) The contribution of NMDA and non-NMDA receptors to fast and slow transmission of sensory information in the rat SI barrel cortex. J Neurosci 13:2149-2160.

Armstrong-James M, Diamond ME, Ebner FF (1994) An innocuous bias in whisker use in adult rat modifies receptive fields of barrel cortex neurons. J Neurosci 14:6978-6991.

Baron JC (1991) Testing cerebral function: will it help the understanding or diagnosis of central nervous system disease? Ciba Found Symp 163:250-261.

Belayev L, Busto R, Zhao W, Ginsberg MD (1995) HU-211, a novel noncompetitive $N$-methyl-D-aspartate antagonist, improves neurological deficit and reduces infarct volume after reversible focal cerebral ischemia in the rat. Stroke 26:2313-2319.

Benuskova L, Rema V, Armstrong-James M, Ebner FF (2001) Theory for normal and impaired experienced-dependent plasticity in neocortex of adult rats. Proc Natl Acad Sci USA 98:2797-2802.

Bienenstock EL, Cooper LN, Munro PW (1982) Theory for the develop- ment of neuron selectivity: orientation specificity and binocular interaction in visual cortex. J Neurosci 2:32-48.

Blinzinger K, Kreutzberg G (1968) Displacement of synaptic terminals from regenerating motoneurons by microglial cells. Z Zellforsch Mikrosk Anat 85:145-157.

Boyeson MG, Feeney DM (1990) Intraventricular norepinephrine facilitates motor recovery following sensorimotor cortex injury. Pharmacol Biochem Behav 35:497-501.

Buchkremer-Ratzmann I, Witte OW (1997) Extended brain disinhibition following small photothrombotic lesions in rat frontal cortex. NeuroReport 8:519-522.

Buchkremer-Ratzmann I, August M, Hagemann G, Witte OW (1996) Electrophysiological transcortical diaschisis after cortical photothrombosis in rat brain. Stroke 27:1105-1111.

Cappa SF, Perani D, Grassi F, Bressi S, Alberoni M, Franceschi M, Bettinardi V, Todde S, Fazio F (1997) A PET follow-up study of recovery after stroke in acute aphasics. Brain Lang 56:55-67.

Clarey JC, Tweedale R, Calford MB (1996) Interhemispheric modulation of somatosensory receptive fields: evidence for plasticity in the primary somatosensory cortex. Cereb Cortex 6:196-206.

Connors BW, Gutnik MJ (1990) Intrinsic firing patterns of diverse neocortical neurons. Trends Neurosci 13:99-104.

Diamond ME, Armstrong-James M, Ebner FF (1993) Experiencedependent plasticity in adult rat barrel cortex. Proc Natl Acad Sci USA 90:2082-2086.

Diamond ME, Huang W, Ebner FF (1994) Laminar comparison of somatosensory cortical plasticity. Science 265:1885-1888.

Dietrich WD (1998) Neurobiology of stroke. Int Rev Neurobiol 42:55-101.

Dobkin JA, Levine RL, Lagreze HL, Dulli DA, Nickles RJ, Rowe BR (1989) Evidence for transhemispheric diaschisis in unilateral stroke. Arch Neurol 46:1333-1336.

Feeney DM (1997) From laboratory to clinic: noradrenergic enhancement of physical therapy for stroke or trauma patients. Adv Neurol 73:383-394. Feeney DM, Baron JC (1986) Diaschisis. Stroke 17:817-830.

Fox K, Armstrong-James M (1986) The role of the anterior intralaminar nuclei and $N$-methyl D-aspartate receptors in the generation of spontaneous bursts in rat neocortical neurons. Exp Brain Res 63:505-518.

Huang W, Armstrong-James M, Rema V, Diamond ME, Ebner FF (1998) Contribution of the supragranular layers to sensory processing and plasticity in adult rat barrel cortex. J Neurophysiol 80:3261-3271.

Hurwitz BE, Dietrich WD, McCabe PM, Watson BD, Ginsberg MD, Schneiderman N (1990) Sensory-motor deficit and recovery from thrombotic infarction of the vibrissal barrel-field cortex. Brain Res 512:210-220.

Hurwitz BE, Dietrich WD, McCabe PM, Alonso O, Watson BD, Ginsberg MD, Schneiderman N (1991) Amphetamine promotes recovery from sensory-motor integration deficit after thrombotic infarction of the primary somatosensory rat cortex. Stroke 22:648-654.

Infeld B, Davis SM, Lichtenstein M, Mitchell PJ, Hopper JL (1995) Crossed cerebellar diaschisis and brain recovery after stroke. Stroke 26:90-95.

Jones TA, Kleim JA, Greenough WT (1996) Synaptogenesis and dendritic growth in the cortex opposite unilateral sensorimotor cortex damage in adult rats: a quantitative electron microscopic examination. Brain Res 733:142-148.

Juhasz C, Kamondi A, Szirmai I (1997) Spectral EEG analysis following hemispheric stroke: evidences of transhemispheric diaschisis. Acta Neurol Scand 96:397-400.

Keller A, White EL (1987) Synaptic organization of GABAergic neurons in the mouse SmI cortex. J Comp Neurol 262:1-12.

Korelek K-A, Jensen KF, Killackey HP (1988) Evidence for two complementary patterns of thalamic input to the rat somatosensory cortex. Brain Res 463:346-351.

Kotila M, Waltimo O (1992) Epilepsy after stroke. Epilepsia 33:495-498.

Lagreze HL, Levine RL, Pedula KL, Nichels RJ, Sunderland JS, Rowe BR (1987) Contralateral flow reduction in unilateral stroke: evidence for transhemispheric diaschisis. Stroke 18:882-886.

Lu S-M, Lin RC-S (1992) Thalamic afferents of the rat barrel cortex: a lightand electron-microscopic study using Phaseolus vulgaris leucoagglutinin as an anterograde tracer. Somatosens Mot Res 10:1-16.

McAllister AK, Lo DC, Katz LC (1995) Neurotrophins regulate dendritic growth in developing visual cortex. Neuron 15:791-803.

McCormick DA, Connors BW, Lighthall JW, Prince DA (1985) Compara- 
tive electrophysiology of pyramidal and sparsely spiny stellate neurons of the neocortex. J Neurophysiol 54:782-806.

Nudo RJ (1999) Recovery after damage to motor cortical areas. Curr Opin Neurobiol 9:740-747.

Olavarria J, van Sluyters RC, Killackey HP (1984) Evidence for the complementary organization of callosal and thalamic connections within rat somatosensory cortex. Brain Res 291:364-368.

Pazos AJ, Orezzoli SL, McCabe PM, Dietrich WD, Green EJ (1995) Recovery of vibrissae-dependent behavioral responses following barrelfield damage is not dependent upon the remaining somatosensory cortical tissue. Brain Res 689:224-232.

Pidoux B, Verley R (1979) Projections on the cortical somatic I barrel subfield from ipsilateral vibrissae in adult rodents. Electroencephalogr Clin Neurophysiol 46:715-726.

Prince DA, Jacobs KM, Salin PA, Hoffman S, Parada I (1997) Chronic focal neocortical epileptogenesis: does disinhibition play a role? Can J Physiol Pharmacol 75:500-507.

Redecker C, Wang W, Fritschy J-M, Witte OW (2002) Widespread and long-lasting alterations in GABAa-receptor subtypes after focal cortical infarcts in rats: mediation by NMDA-dependent processes. J Cereb Blood Flow Metab 22:1463-1475.

Reinecke S, Dinse HR, Reinke H, Witte OW (2003) Induction of bilateral plasticity in sensory cortical maps by small unilateral cortical infarcts in rats. Eur J Neurosci 17:623-627.

Rema V, Ebner FF (1999) Effect of enriched environment rearing on impairments in cortical excitability and plasticity after prenatal alcohol exposure. J Neurosci 19:10993-11006.

Rema V, Armstrong-James M, Ebner FF (1998a) Experience-dependent plasticity of adult rat $\mathrm{S} 1$ cortex requires local NMDA receptor activation. J Neurosci 18:10196-10206.

Rema V, Armstrong-James M, Jenkinson EW, Ebner FF (1998b) Short-term enriched experience potentiates whisker-pairing plasticity of barrel cortex neurons in adult rats. Soc Neurosi Abstr 24:116.

Ross DT, Ebner FF (1990) Thalamic retrograde degeneration following cortical injury: an exocitotoxic process? Neuroscience 35:525-550.

Sachdev RS, Lu SM, Wiley RG, Ebner FF (1998) The role of the basal forebrain cholinergic projection in somatosensory cortical plasticity. J Neurophysiol 79:3216-3228.

Sachdev R, Egli M, Stonecypher M, Wiley RG, Ebner FF (2000) Usedependent cortical plasticity in acetylcholine depleted adult rats. J Neurophysiol 84:1971-1981.

Segal M, Auerbach JM (1997) Muscarinic receptors involved in hippocampal plasticity. Life Sci 60:1085-1091.

Shuler MG, Krupa DJ, Nicolelis MAL (2001) Bilateral integration of whisker information in the primary somatosensory cortex of rats. J Neurosci 21:5251-5261.

So EL, Annegers JF, Hauser WA, O’Brien PC, Whisnant JP (1996) Populationbased study of seizure disorders after cerebral infarction. Neurology 4:350-355.

von Monakow C (1914) Die Lokalisation im Grosshirm un der Abbau der Funktion durch Kortikale Herde, pp 26-34. Wiesbaden, Germany: Bergman.

Witte OW (1998) Lesion-induced plasticity as a potential mechanism for recovery and rehabilitative training. Curr Opin Neurol 11:655-662.

Witte OW, Stoll G (1997) Delayed and remote effects of focal cortical infarctions: secondary damage and reactive plasticity. Adv Neurol 73:207-227.

Wong-Riley MT, Welt C (1980) Histochemical changes in cytochrome oxidase of cortical barrels after vibrissal removal in neonatal and adult mice. Proc Natl Acad Sci USA 77:2333-2337.

Zarei M, Raevsky VV, Dawe GS, Stephenson JD (2001) Changes in sensitivity of cholinoceptors and adrenoceptors during transhemispheric cortical reorganization in rat SmI. Brain Res 888:267-274. 